\title{
O "paraíso obscuro do mundo": territorialidades e desafios da influência cultural Brasileira no Leste Paraguaio
}

Rodrigo Ramos Hospodar Felippe Valverde*

\section{Resumo}

Esse artigo pretende lançar nova luz sobre a influência das culturas brasileiras no Leste do Paraguai, tomando para si uma abordagem que chama atenção para a organização territorial. Entendemos que a influência cultural mencionada reforça tendências de uma hegemonia territorial que vai além da recente discussão da propriedade de terras na fronteira. Seguindo as definições de território e de territorialidade propostas por Robert Sack, é necessário aceitar que o controle sobre uma área pode ser realizado por diferentes tipos de trocas, incluindo comunicações, educação, cultura e sinalização. Para realizar esse trabalho, sugerimos como base tanto a avaliação de documentos de instituições (governos do Brasil e do Paraguai, MERCOSUL, UNASUL), quanto o olhar lançado sobre os jornais paraguaios. Esperamos esclarecer alguns dos desafios que a proximidade e a cooperação econômica do MERCOSUL estão enfrentando nesse momento.

Palavras-chave: Imperialismo; Territorialidade; Cultura; Brasil; Paraguai.

Possui graduação em Geografia pela Universidade Federal do Rio de Janeiro (1999), mestrado em Geografia pela Universidade Federal do Rio de Janeiro (2003) e doutorado em Geografia pela Universidade Federal do Rio de Janeiro (2007). Atualmente é Professor Doutor da Universidade de São Paulo e pesquisador associado da Universidade Federal do Rio de Janeiro (rvalverde @ usp.br).

Geosul, Florianópolis, v. 28, n. 55, p 55-76, jan./jun. 2013 
VALVERDE, R.R.H.F. O "paraíso obscuro do mundo": territorialidades ...

The "world's obscure paradise": territorialities and challenges of Brazilian cultural influence in East Paraguay

\section{Abstract}

This article intends to shed a light on the influence of Brazilian cultures in East Paraguay, taking an approach that calls attention to the territorial organization. I understand that this cultural influence is reinforcing tendencies of a territorial hegemony that goes further than the recent discussion of land ownership in the border. Following the definitions of territory and territoriality as presented by Robert Sack, it is necessary to accept that the control over an area can be made through several types of exchanges, including communication, education, culture and signalization. In order to do so, I suggest evaluating documents from institutions (governments of Brazil and Paraguay, MERCOSUR and UNASUR), as well as Paraguayans newspapers. I expect to clarify some of the challenges that the proximity and the economic cooperation of MERCOSUR are facing at the beginning of the XXI century.

Key words: Imperialism; Territoriality; Culture; Brazil; Paraguay.

\section{Introdução}

Em meio ao debate recente sobre a presença de trabalhadores rurais e proprietários de terras brasileiros no Leste do Paraguai, de tempos em tempos faz-se apelo através dos veículos midiáticos a episódios que, a princípio, não tem conexão direta com os conflitos fundiários atuais. Entre os menos esperados, são encontradas alusões à arrogância brasileira como o episódio ocorrido em Julho de 2010, durante a Copa do Mundo. Uma emissão televisiva do canal Sportv teria preparado um quadro jocoso sobre o Paraguai, chamado de "paraíso obscuro do mundo", ultrapassando em muito qualquer limite tolerável de rivalidade futebolística. No vídeo, são ridicularizadas algumas referências da cultura paraguaia, desde aspectos tradicionais, como a língua 
VALVERDE, R.R.H.F. O “paraíso obscuro do mundo": territorialidades ...

guarani, e o prato yopara, além de paisagens com imagens retiradas de áreas pobres até referências populares mais novas da cultura popular, como a modelo Larissa Riquelme e a música de Ramonita Vera. Em um editorial de 05/07/2010, o jornal La Nacion respondia ao ocorrido:

Los canales de TV locales reprodujeron ayer un 'corto' de Sport TV de Globo (...) en la que busca por todos los medios denigrar nuestra cultura, nuestros atractivos turísticos, el "valor" de la moneda local en el mercado bursátil y desprecia la tarea de la albirroja (...). En la última parte del video ironizan sobre nuestras comidas y nuestras costumbres, señalando en esta parte que la comida es una "maravilla" mientras pasaban imágenes de un hombre con rasgos paraguayos comiendo frituras. Además, ironizan sobre nuestros caminos 'Si no le gusta el océano, Paraguay es el lugar ideal para tomarse unas vacaciones', se escucha en una parte del relato. (...) ¿qué dirá ahora Sport TV de Globo? ¿Tendrá la suficiente humildad para la autocrítica, o seguirán con la hipocresía de vivir a espaldas de sus grandes problemas (...) y hacer creer siempre que Ciudad del Este es el oasis del contrabando cuando que es su gente la que mayor provecho saca del desorden en Triple Frontera? Para la mayoría de los paraguayos este documental fue realmente decepcionante, por todos los vínculos que nos unen (...) (LA NACION, 05/07/2010).

Porém, aos olhos de muitos paraguaios, as consequências socioterritoriais da influência da cultura brasileira podem ser ainda mais graves do que o referido episódio. Com peso demográfico crescente e estimado na casa de 500.000, os brasileiros residentes no Paraguai e os seus descendentes, oficialmente paraguaios, já representam por si sós um enorme aporte dentro dos símbolos e representações que compõem a massa heterogênea da cultura paraguaia. Quando consideramos ainda que o próprio acesso ao lazer, à informação, aos equipamentos culturais, à moda e à educação na área leste do Paraguai, sobretudo no Departamento de 
VALVERDE, R.R.H.F. O "paraíso obscuro do mundo": territorialidades ...

Alto Paraná, amplifica ainda mais a influência brasileira, é possível discutir os desafios e os riscos da hegemonia de nossa cultura no país vizinho aos olhos dos próprios referenciais paraguaios.

Para os fins desse artigo, consideramos então que a fronteira será observada nos limites do Departamento do Alto Paraná, dos seus usos e de seus símbolos. Tomamos como fonte os agentes sociais paraguaios e "brasiguaios", de modo a conferir visibilidade à representações pouco conhecidas no Brasil. Ao fazê-lo, não queremos reforçar um discurso sectário, mas apenas chamar atenção para a forma pela qual os conflitos sociais ganham sentidos simbólicos que podem afetar os sentidos formais de fronteira, Tratamos então de uma fronteira que, via de regra, apresenta conflitos socioterritoriais de sentido variado, apesar da base jurídica e institucional dos países apresentarem certa aproximação e tradição de ação conjunta.

Em meio à união aduaneira do Mercosul, às assimetrias econômicas entre os diferentes Estados, aos conflitos tributários e aos projetos conjuntos para os setores de energia e de grandes investimentos, a integração cultural do bloco foi colocada em segundo plano, salvo raras exceções. Com exceção de leis e incentivos ao ensino de línguas, das trocas de representações artísticas e ao livre trânsito, pouco foi dito e realizado para lidar com os possíveis conflitos culturais entre os países signatários. Tampouco foram repetidos no Mercosul os cuidados e críticas realizadas a época de discussão do projeto da Área de Livre Comércio das Américas (ALCA), que refletia as intenções do governo e do mercado norte-americanos de aceder aos mercados e serviços de comunicação, de cultura e de ensino. Tal situação apenas reforça os atritos e cria uma lacuna de regulamentação.

A posição de hegemonia brasileira no subcontinente não é apenas resultado do PIB brasileiro ou de sua enorme população: muitos pesquisadores entendem que essa posição reflete uma crescente influência cultural do Brasil nas regiões de fronteira (HAESBAERT \& SANTA BARBARA, 2001; SOUCHAUD, 2002; SPRANDEL, 2006). Ainda que se considere a fronteira por 
VALVERDE, R.R.H.F. O "paraíso obscuro do mundo": territorialidades ...

intermédio de sua "permeabilidade", o que sugere a influência mútua entre as culturas e a existência de uma zona de transição, tomamos como pressuposto desse artigo que os recursos técnicos diferenciados e a proeminência brasileira no Mercosul conferem uma enorme assimetria na difusão e na assimilação cultural.

Segundo editorial do Jornal Ultima Hora de 2003, essa influência seria resultado da agressividade e da competitividade do Estado e dos empresários brasileiros que, através de ação direta e intencional, pretendem redefinir padrões de consumo e de política no Paraguai. Nesse processo, as próprias condições para a regulação da ação privada e para a compensação das assimetrias poderiam ser limitadas. Nas palavras usadas pelos críticos:

El Estado debe ocuparse de los problemas generados por la descontrolada afluencia de colonos brasileños a nuestro país. La presencia masiva de inmigrantes brasileños (...) Nesse contexto, esse artigo pretende diagnosticar os conflitos gerados pela presença de elementos das culturas brasileiras em áreas transfronteiriças. Mais precisamente, colocamos como nossa tarefa esclarecer sinais de territorialidades brasileiras no Leste do Paraguai, definindo ações e reações por diversos agentes e lançando desafios à integração. É preciso destacar que esses conflitos são análogos a outros existentes, como aqueles que envolvem a construção do "Cristo del Pacífico" no Peru. No entanto, para os fins desse artigo, nos limitamos ao caso paraguaio.

Dividimos esse artigo em duas partes. Na primeira, faremos um esforço em demonstrar que o conceito de territorialidade de Sack (1986) é compatível com as concepções de imperialismo cultural. Esperamos com isso abrir vias de avaliação de dinâmicas socioterritoriais que nem sempre são exploradas na geografia. Em segundo lugar, usaremos os documentos do Mercosul e as notícias de periódicos paraguaios como base para avaliar possíveis excessos e conflitos em relação à influência cultural brasileira. Apesar de entendermos que cada um desses registros possui seus limites de interpretação e de representação dentro do contexto paraguaio, tais 
VALVERDE, R.R.H.F. O “paraíso obscuro do mundo": territorialidades ...

fontes nos apresentam um quadro geral, no qual nossas perspectivas se chocam com outras, oriundas do país vizinho.

plantea complejos problemas de asimilación cultural,impacto ambiental, de uso de la tierra, de desplazamiento de la población campesina, delegalidad y de soberanía. Es sencillamente inconcebible que el Estado paraguayo continúe sin una política que comprenda esa realidad y regule ese proceso migratório que ya lleva más de cuatro décadas (ULTIMA HORA, 19/09/2003, p. 24).

Ainda que se considerem os exageros no discurso, é preciso conferir o devido peso ao fato de que os 40 anos de afluxo contínuo de brasileiros concentrados geograficamente no leste paraguaio interfere de modo sistemático sobre a forma como o Estado se reproduz física e simbolicamente. De acordo com Laino:

não se pode observar sem preocupação o fenômeno que gera a expansão brasileira sobre os limites fronteiriços paraguaios: suas terras, seus recursos naturais, sua moeda, sua divisa, seu idioma, seus costumes, se encontram dentro de um acelerado processo de desnacionalização (p. 07). E como complemento, a moeda, os costumes e muitas vezes até a educação e o idioma das fronteiras nacionais com o Brasil já não são paraguaios (LAINO, 1979, p. 35).

Nesse contexto, esse artigo pretende diagnosticar os conflitos gerados pela presença de elementos das culturas brasileiras em áreas transfronteiriças. Mais precisamente, colocamos como nossa tarefa esclarecer sinais de territorialidades brasileiras no Leste do Paraguai, definindo ações e reações por diversos agentes e lançando desafios à integração. É preciso destacar que esses conflitos são análogos a outros existentes, como aqueles que envolvem a construção do "Cristo del Pacífico" no Peru. No entanto, para os fins desse artigo, nos limitamos ao caso paraguaio.

Dividimos esse artigo em duas partes. Na primeira, faremos um esforço em demonstrar que o conceito de territorialidade de Sack (1986) é compatível com as concepções de imperialismo cultural. Esperamos com isso abrir vias de avaliação de dinâmicas 
VALVERDE, R.R.H.F. O "paraíso obscuro do mundo": territorialidades ...

socioterritoriais que nem sempre são exploradas na geografia. Em segundo lugar, usaremos os documentos do Mercosul e as notícias de periódicos paraguaios como base para avaliar possíveis excessos e conflitos em relação à influência cultural brasileira. Apesar de entendermos que cada um desses registros possui seus limites de interpretação e de representação dentro do contexto paraguaio, tais fontes nos apresentam um quadro geral, no qual nossas perspectivas se chocam com outras, oriundas do país vizinho.

\section{As territorialidades da hegemonia cultural brasileira no Leste Paraguaio}

Ao reconhecer a presença e a força das representações culturais brasileiras dentro do Paraguai, é preciso fazer inicialmente algumas ressalvas. Em primeiro lugar, que diversos instrumentos de ordem, sentidos e atores heterogêneos compõem a sua realização, tal como é possível averiguar através dos estudos das línguas, dos meios de comunicação, dos hábitos, das políticas de ensino e do espaço banal, relativo às sociabilidades. Em segundo lugar, é preciso também tomar em consideração que a incidência dessa influência cultural não fere necessariamente as leis brasileiras ou paraguaias, mesmo em casos extremos. As assimetrias, os conflitos e as dominações estão, em grande parte, inseridos nos sistemas jurídicos e, como veremos, são dependentes das suas lacunas. Em terceiro lugar, tais influências culturais não são sinônimas de violência em sentido estrito, apesar de que, entre os seus efeitos indiretos, tais conflitos possam ocorrer. Por último, é preciso considerar que o debate aqui desenvolvido não pretende realizar uma defesa estrita de políticas culturais nacionalistas e tradicionalistas e tampouco acredita que as trocas culturais sejam negativas ou que irão nos conduzir à guerra. O que se coloca aqui é que a onipresença de elementos das culturas brasileiras na faixa fronteiriça ao leste do Paraguai tem por consequência uma série de conflitos que tem interesse geográfico. 
VALVERDE, R.R.H.F. O “paraíso obscuro do mundo": territorialidades ...

Duas perguntas gerais ganham importância nesse artigo. A primeira gira em torno de como a cultura pode exprimir uma relação de dominação de cunho imperialista. Podemos adiantar que, inicialmente, a resposta a essa pergunta está mais tradicionalmente conectada à difusão de representações do mundo de sentido etnocentrista, preocupada em estabelecer uma hierarquia de culturas dependente de uma visão única de desenvolvimento que pressupõe a redução da diversidade (BOURDIEU e WACQUANT, 2002).

A segunda pergunta, mais especificamente geográfica, se refere a como esse imperialismo cultural pode influenciar a organização territorial e suas relações de poder. Para tanto, nos apoiamos nos princípios introduzidos por Sack (1986) para reforçar que o domínio territorial não se exprime unicamente através do controle físico do terreno, da presença ostensiva, dos equipamentos colocados ou do controle do acesso. Como o autor ressaltou, o domínio de práticas comunicativas e a sinalização do domínio territorial são capazes de conferir novo dinamismo ao território, que pode incrementar ou ao menos reproduzir as cadeias de dominação. As ideias gerais de Sack podem ser sintetizadas da seguinte forma: a territorialidade seria simultaneamente uma forma de classificação de área, uma forma de controle de acesso e ainda um modo de comunicação (VALVERDE, 2004, p. 121). Nas palavras do autor, podemos traduzir o conceito com maior precisão por intermédio de um conjunto formado pelas suas características fundamentais:

Territoriality involves a form of classification that is extremely efficient under certain circumstances. Territoriality classifies, at least in part, by area rather than by type (...). Territoriality can be easy to communicate because it requires only one kind of marker or sign - the boundary. The territorial boundary may be the only symbolic form that combines direction in space and a statement about possession or exclusion. Territoriality can be the most efficient strategy for enforcing control, if the 
VALVERDE, R.R.H.F. O "paraíso obscuro do mundo": territorialidades ...

distribution in space and time of the resources or things to be controlled fall well between ubiquity and unpredictability. (...) Territoriality provides a means of reifying power. Power and influence are not always as tangible as are streams and mountains (...). Territoriality makes potentials explicit and real by making them 'visible'. (...) Territoriality can be used to displace attention from the relationship between controller and controlled to the territory. (...) By classifying at least in part by area rather than by kind or type, territoriality helps make relationships impersonal. (SACK, 1986, p. 32-33).

Responder, ainda que parcialmente, pode contribuir tanto para a Geografia Cultural quanto para a Geografia Política, ao sistematizar questões de representação e de poder que são tomadas exclusivamente de forma empírica em nossa ciência. De início, partimos da definição de Schiller sobre imperialismo cultural que afirma:

The concept of cultural imperialism (...) best describes the sum of the processes by which a society is brought into the modern world system and how its dominating stratum is attracted, pressured, forced, and sometimes bribed into shaping social institutions to correspond to, or even promote, the values and structures of the dominating centre of the system. The public media are the foremost example of operating enterprises that are used in the penetrative process. For penetration on a significant scale the media themselves must be captured by the dominating /penetrating power (SCHILLER, 1976, p. 9-10).

Acrescentamos que esse poder hegemônico exerce o seu poder por intermédio do aproveitamento das lacunas de regulamentação que protejam a cultura de um país. Nos referimos, por exemplo, à regras que exigem a preponderância da língua oficial entre os meios de comunicação, às leis que versam sobre o ensino público ou privado, aos limites de concentração dos equipamentos culturais, às taxas e contrapartidas da presença de 
VALVERDE, R.R.H.F. O “paraíso obscuro do mundo": territorialidades ...

bens culturais estrangeiros em território nacional. No contexto latino-americano, a passagem de um modelo fechado, vinculado aos Estados Nacionais para os princípios de um ambiente no qual as trocas intra-bloco são estimuladas ainda carece de maior observação dos efeitos territoriais. Pelas dificuldades técnicas e pela urgência de outros debates, a ata do grupo de trabalho "Comunicações" do Mercosul ilustra essa omissão:

Durante a XXXIX reunião do SGT-1, realizada na cidade de San Miguel de Tucumán na Argentina, o SGT-1 solicitou ao GMC que avaliasse a possibilidade de revogar a Resolução GMC No 24/94 "Harmonização de novas tecnologias em telecomunicações", entendendo que além de ter se tornado obsoleta do ponto de vista técnico, o Mercosul não é o âmbito adequado para harmonizar nem regulamentar tecnologias de telecomunicações (MERCOSUL, 2012, p. 7).

Uma segunda característica sobre o imperialismo cultural se refere à existência de relações privilegiadas ou exclusivas previstas por lei entre as culturas de diferentes países. Isso significa que há maior abertura prevista no sistema jurídico de um país para a presença de capitais e agentes estrangeiros nos setores relativos à cultura. De acordo com as normas do Mercosul, ratificadas por todos os assinantes, a ação dos agentes públicos e privados dos países signatários no setor da cultura não encontra as mesmas condições daqueles oriundos de outras partes do mundo. Com isso, brasileiros podem investir e agir em terreno paraguaio para prover serviços técnicos e culturais que são bloqueados aos agentes de fora do bloco. Enquanto o Estado paraguaio discute um novo marco regulatório para o setor de telecomunicações e o Mercosul se furta de estipular regras claras para regulamentá-lo por falta de uma visão estratégica de suas consequências, empresas brasileiras avançam no controle de equipamentos, serviços e representações. Nesse processo, todos os esforços para evitar o "apagão" no setor de telecomunicações paraguaio vêm acompanhados de um 
VALVERDE, R.R.H.F. O "paraíso obscuro do mundo": territorialidades ...

reordenamento territorial de sua rede. A introdução de tecnologias de fibra ótica a partir de centrais no departamento de Alto Paraná ilustra a redefinição de área de influência, que flutuam de empresas argentinas para empresas brasileiras na atualidade:

La compañía Oi del Brasil prestará sus servicios en el país. En la Comisión Nacional de Telecomunicaciones (Conatel) ya se dio el visto bueno para que la empresa pueda comenzar a operar en el Este del país en forma mayorista. Según el proyecto técnico presentado ante el ente regulador, la empresa tiene prevista la construcción de un anillo de fibra óptica en el departamento de Alto Paraná, pero aún no se conoce el monto de la inversión de la compañía en el país. Actualmente la provisión mayorista en el país la realizan las compañías de Argentina Telefónica y Telecom. Con esta nueva opción, las empresas de todo el país que deseen tener internet de la compañía brasileña podrán obtener la señal de la misma, pero deberán extender sus conexiones hasta el departamento de Alto Paraná para proveerse de los servicios (LA NACION, 21/11/2011).

Apenas recentemente o MERCOSUL abriu um fórum para discussão e compensação dos conflitos referentes às diferentes capacidades de concorrência e aos diferentes pesos das economias nacionais dos países signatários. Isso significa que, por um longo período, agentes econômicos do Brasil e da Argentina tiveram grandes vantagens comparativas ao exercer suas atividades no Paraguai e no Uruguai. A assimetria econômica brasileira gera preocupações no sentido em que pode criar relações de dependência além das trocas econômicas: a própria forma como parte do Paraguai se vê ou olha para os seus vizinhos pode ser alterada. Causa preocupação, entre outros elementos, o grande número de emissoras de rádio que tem transmissões em português ou a concentração de parabólicas voltadas para o Brasil no Departamento de Alto Paraná. Tal fato se torna ainda mais grave quando se nota que o provimento de serviços de telecomunicações de controle paraguaio é particularmente falho em regiões de 
VALVERDE, R.R.H.F. O "paraíso obscuro do mundo": territorialidades ...

fronteira. Essa preocupação pode ser observada no clamor pelo controle e limitação da prática de instalação de antenas parabólicas no Paraguai:

Los operadores de TV por cable reclaman al Gobierno paraguayo hacer frente al constante ingreso de antenas parabólicas y decodificadores, que son utilizados para captar señales satelitales de televisión. Advierten que la instalación de estos aparatos supone una competencia desleal que generará que muchos trabajadores pierdan sus puestos (ABC DIGITAL, 05/07/2011).

Isso significaria, por exemplo, que em uma época de conflitos entre carperos, camponeses sem-terra paraguaios, e produtores brasileiros, ambos teriam acesso à informações quase que exclusivamente através de canais brasileiros ou, pelo menos, com conteúdo em português e com grande influência cultural brasileira. Como apresenta o sociólogo paraguaio Ramon Fogel, de forma enfática:

Brasil es lo país más poderoso, es el país qué más se espandió em toda la región, y entonces eso hace que facilmente nos colonicen; conseguen viren a integrarse a nuestro meyo cómo inmigrantes, si no vienem a colonizarnos haja que sosgladien las divisiones (...). Bueno, prolongan la dinámica de Brasil, este es un fator importante (...). Brasil es más poderoso de la región y nosotros estamos bastante vulnerables nesta asinmetria; esto hace que este tenga la tendencia a colonisarnos, y a esteriotiparnos (FOGEL Apud BALLER, 2006, p. 126).

De fato, a redução da diversidade diante de um processo de uniformização técnica e civilizatória é outra característica marcante dentre as possíveis definições de imperialismo cultural. Através do desenvolvimento do sistema técnico-científico-informacional, define-se com mais facilidade que as relações de trocas culturais não são medidas apenas através da autodefinição dos grupos sociais ou do equilíbrio e da tolerância. Muito frequentemente, os 
VALVERDE, R.R.H.F. O "paraíso obscuro do mundo": territorialidades ...

desníveis técnicos geram conflitos e/ou dominações que podem se cristalizar em cadeias de poder. Nesse processo, diversas práticas tradicionais e/ou informais são lentamente suprimidas da cena pública: língua, costumes, culinária, vestimentas, festas populares, etc. De acordo com Haesbaert e Barbara:

A difusão da cultura e de costumes brasileiros faz com que emissoras de radio, em localidades como Santa Rita e San Alberto, tenham horários onde a transmissão e feita exclusivamente em português. 'Me sinto como se estivesse no Brasil, por causa da teve parabólica e da comida', afirmou uma migrante brasileira em Santa Rita. Existem casos, principalmente entre as gerações mais recentes de brasileiros no Paraguai, em que os imigrantes mantém a tradição de falar o alemão (segundo idioma de muitos brasileiros originários do sul do pais) no âmbito das relações familiares. Já no espaço público fala-se o português, porém na escola existe a obrigatoriedade de comunicar-se somente em espanhol e guarani. O idioma guarani, visivelmente um instrumento cultural de resistência para os paraguaios, vai sendo aos poucos introduzido na comunidade brasileira, que começa a reconhecer o seu papel estratégico nas relações sociais (HAESBAERT; BARBARA, 2001, p. 40).

Como Cervo acrescentou, para cada novo projeto de intervenção pública do Brasil e do Paraguai que se desenha no intuito de reforçar os contatos mútuos, surgem também novas facilidades para o intercâmbio cultural:

[...] prover o Paraguai de comunicações duráveis que lhe abrissem as portas do Brasil e do Atlântico, concluindo a rodovia de Ponta Porã e Pedro Juan Caballero e a ferrovia com terminais em Santos e Porto Esperança; sobre essa base física, firmar entendimentos para cooperação econômica e intercâmbio comercial e cultural (CERVO, 2001, p. 178). 
VALVERDE, R.R.H.F. O "paraíso obscuro do mundo": territorialidades ...

Porém, paralelamente as trocas estatais, a definição de padrões de consumo e a orientação das trocas se constituem em outras características distintivas do imperialismo cultural. Por intermédio da hegemonia sobre os sistemas, serviços e equipamentos culturais, definem-se novos padrões de consumo a partir de princípios que são externos ao país. As trocas culturais seriam mais ou menos controladas de acordo com a dimensão dessa presença estrangeira no setor, sem necessidade de maior rigor ou violência. Os inúmeros mecanismos de reificação do domínio inclusos no setor já seriam suficientes para manter regular o sentido preferencial das trocas culturais. Dito de forma ainda mais clara, o fato de parte significativa de paraguaios vivenciarem a música brasileira em seu país, de assistir jornais, partidas de futebol e novelas brasileiras, de falar em português, usar serviços de comunicação e de comercializar roupas fabricadas no Brasil, entre outras trocas culturais, já os tornam preferencialmente orientados à sociedade brasileira. Modas, ideias e produtos lançados no Brasil encontrariam então no Paraguai uma área de influência direta, sem necessidade de grandes investimentos específicos para garantir a sua difusão.

De acordo com Albuquerque:

A imagem do Brasil como uma nação moderna, civilizada e superior aos países vizinhos está presente na ideologia de muitos 'brasiguaios' que se confrontam com as culturas camponesas e indígenas daquele país. Eles se apresentam como 'missionários' da civilização e estariam ensinando aos paraguaios como se tornarem 'modernos' e 'trabalhadores'. Os conflitos culturais entre imigrantes e paraguaios e os estereótipos construídos nesse cenário de fronteiras aumentam as tensões cotidianas. A autoidentificação dos imigrantes como 'trabalhadores', 'pioneiros' e a classificação dos paraguaios como 'preguiçosos', 'corruptos' e 'sujos' simbolizam assimetrias de poder entre os grupos locais e as nações. Contudo, as relações de poder não são estáticas e consolidadas. Os 
VALVERDE, R.R.H.F. O "paraíso obscuro do mundo": territorialidades ...

grupos subordinados podem adquirir força política e atacar os interesses dos grupos estabelecidos. Os movimentos camponeses têm reagido contra essas classificações pejorativas atribuídas pelos imigrantes brasileiros, por outros estrangeiros e por setores da elite política e econômica paraguaia (ALBUQUERQUE, 2009, p. 149).

É exatamente esse o caso encontrado no discurso de Tranquilo Favero, nascido no Brasil, e que hoje é o maior produtor individual de soja no Paraguai. Em entrevista amplamente divulgada, Favero avalia pejorativamente os camponeses paraguaios, defende o uso da violência contra movimentos sociais e ironiza a língua e outros símbolos culturais locais. Em suas palavras:

Diplomacia você pode usar com pessoas cultas... só que... você sabe o dito popular que diz: a mulher do malandro obedece só com pau... estamos lidando com pessoas de tamanha ignorância que com diplomacia você não soluciona. (...)Um amigo me disse que eu não precisaria aprender guarani se tivesse muitos deles no bolso (FAVERO Apud CAPRIGLIONE, 2012).

Todas essas características que definem as possíveis práticas do imperialismo cultural reforçam em muito as territorialidades dos grupos brasileiros no Paraguai. O controle territorial se constituiria muito além da presença física e do poder das armas. Antes mesmo de toda e qualquer ação sistemática de controle de acesso, da necessidade de que agentes econômicos brasileiros atuem de forma mais agressiva para resguardar seus interesses, já se consolida um ambiente no qual a sua presença é qualificada. A simples sinalização da origem brasileira e o referenciamento de certa prática ou produto como "brasileiro", abre-se a perspectiva de sua difusão quase que irrestrita na sociedade paraguaia. Como apresentou Albuquerque:

A relação entre conflito, dominação e integração indica a especificidade dessa região de fronteira de forte presença de 
VALVERDE, R.R.H.F. O "paraíso obscuro do mundo": territorialidades ...

brasileiros e seus descendentes. (...) A nação brasileira também se tornou mais visível, com os maiores fluxos migratórios, os meios de comunicação, a compra de antenas parabólicas e a instalação de rádios locais durante as décadas de 1980 e 1990. A influência brasileira hoje é predominante no idioma, nos meios de comunicação, na música e na culinária. Entretanto, a existência de rádios com programação em espanhol e de sistemas de TV a cabo, em algumas cidades, a partir 2002, tem favorecido a ampliação de informações sobre o Brasil e o Paraguai e uma maior aproximação de alguns imigrantes à sociedade paraguaia (ALBUQUERQUE, 2010, p. 84).

A hierarquização das representações culturais seria a última vertente do imperialismo cultural: através das políticas de educação e de comunicação, seria possível influenciar o modo pelo qual tais representações são absorvidas e avaliadas. De acordo com o grupo ou classe social que estabelece o filtro de análise, aquelas representações que simbolizassem o status social, o progresso, a ordem dominante e a felicidade ganhariam maior destaque, pouco importando a tradição, as divergências existentes ou a origem da ideia.

Entre as opiniões que emergem acerca das políticas culturais no Paraguai, muitas revelam preocupação pela perspectiva de redução nas representações artísticas de origem paraguaia. Se, no passado, devido a certo grau de isolamento paraguaio em relação aos vizinhos e à distância física de norte-americanos e europeus, foi possível o desenvolvimento de uma cultura híbrida paraguaia, compondo elementos da colonização espanhola, da presença indígena guarani e de elementos inovadores, teme-se hoje que a presença ostensiva de elementos das culturas brasileiras, tão próximas e tão potencializadas pelo domínio do setor cultural, sejam muito mais nocivos ao país. De acordo com o músico paraguaio Victor Brítez:

Los brasileños no solo plantan soja transgénica sino que nos imponen su cultura en la frontera, su lengua, su dinero (...). 
VALVERDE, R.R.H.F. O "paraíso obscuro do mundo": territorialidades ...

Es un fenômeno que además de cultural, es político y económico. Es de anexión directa. (...) Obviamente se necesita una política contraria a eso y no creo que este gobierno pueda impulsar algo favorable en este sentido (ALVAREZ, 09/05/2004, p. 39).

O ponto de vista único surgiria então sem que se constituísse uma mescla de representações culturais devido a enorme assimetria socioeconômica. No Paraguai, parece ser particularmente forte o argumento de que não há real integração cultural entre brasileiros e paraguaios. Ainda que se destaquem os possíveis efeitos positivos da presença brasileira na balança comercial paraguaia, os custos da fragmentação do tecido social e da autoestima paraguaia são, para muitos, injustificáveis. De acordo com o relato transcrito por Galeano e Yore:

Hay que decir no hay la integración de verdad. Hay una cultura totalmente diferente entre los paraguayos y los brasileños, la lengua es diferente, la tradición diferente, la fé diferente. Todo eso hace que, cuando hay un encuentro, una charla, todo el grupo está escuchando, está participando. Cuando hay una cena, puede se que estén allí juntos, más terminada, brasileños e paraguayos... se separan. También está la mentalidad (...). Los brasileños conservan su tradición y cultura; los alemanes hablan el alemán en casa; los italianos y polacos un poco menos. Los paraguayos hablan en guarani en casa (...) Después también está el nível cultural y económico. Ellos (los paraguayos) piensan que los brasileños tienen plata, pueden pagar. Los paraguayos, no (Apud GALEANO e YORE, 1994b, p.100).

\section{Considerações finais}

A guisa de conclusão, a troca de produtos culturais entre Brasil e Paraguai se desenharia como unilateral, mesmo nos casos em que falamos da presença de produtos formais ou informais de origem paraguaia em território brasileiro. Por exemplo, as redes de contrabando ou de tráfico de drogas que se estabelecem no sentido 
VALVERDE, R.R.H.F. O "paraíso obscuro do mundo": territorialidades ...

Paraguai-Brasil, na maior parte dos casos, é capitaneada por agentes econômicos brasileiros que se estabelecem no país vizinho, aproveitando-se do pequeno controle mútuo entre os dois países. Nesse contexto, a própria imagem pejorativa criada no Brasil para reduzir o Paraguai, focada na marginalidade e tendo como símbolo o caos na tríplice fronteira e os shoppings centers de Ciudad Del Este, é produto direto da influência dos padrões de consumo e da ação direta da economia brasileira.

Por outro lado, a língua guarani parece ter sido revalorizada como questão fundamental de formação territorial, ganhando inclusive maior formalização como elemento político paraguaio. Os esforços para o seu reconhecimento como língua oficial do Mercosul e para a sua introdução mais regular no ensino público se mostram como derivações dos conflitos atuais. Como apresentou Albuquerque:

guarani se constitui como a principal barreira entre os paraguaios e os imigrantes que não falam esse idioma. Muitos paraguaios comentam que os brasileiros não aprendem o guarani porque são bastante nacionalistas e buscam preservar a língua portuguesa. Nesse sentido, os imigrantes estariam colocando em perigo a identidade nacional paraguaia, pois estão 'abrasileirando' todos os territórios próximos do limite internacional com o Brasil (ALBUQUERQUE, 2010, p. 586).

No entanto, é preciso lembrar que a língua é uma barreira apenas parcial, sobretudo em contexto de fluidez da fronteira, de estímulo ao aprendizado mútuo e de assimetria no controle dos serviços de telecomunicação. De uma forma geral, tanto em nível internacional quanto em nível regional, há estímulos variados à coexistência linguística (GOMES, 1997). Também é preciso considerar que as relações de dominação técnica-econômica não são sensíveis a essas diferenças culturais. Além disso, as difusões de telecomunicações por si sós já promovem em certo grau a homogeneidade. 
VALVERDE, R.R.H.F. O "paraíso obscuro do mundo": territorialidades ...

Nesse sentido, reforçamos que as manifestações mútuas de xenofobia entre brasileiros e paraguaios que são observadas na atualidade aparecem muito mais como resultados das assimetrias no território do que por uma suposta "incompatibilidade cultural". $\mathrm{O}$ elemento decisivo para o reordenamento das trocas culturais será, justamente, o campo de forças que contrapõe as regulamentações e iniciativas diretas das instituições públicas na região (Brasil, Paraguai, Mercosul, Unasul) e as assimetrias econômicas observadas. Talvez fosse possível considerar ainda as iniciativas variadas que tomam lugar na sociedade, como as rádios comunitárias. Porém, diante do poder de mobilização e de disrupção observados pelos grandes agentes, tais iniciativas se mostram pouco efetivas e duradouras: as próprias rádios comunitárias podem ser reduzidas ou suprimidas durante as novas regulamentações que se desenham. Dessa forma, ainda que se observem alguns esforços para o fortalecimento de uma "identidade Mercosulina", o cenário que se observa hoje é de clara hegemonia cultural brasileira sobre o leste paraguaio, em uma dinâmica territorial que prescinde do controle direto. Os fechamentos e aberturas da fronteira são orientados através das representações criadas por agentes simpáticos à influência brasileira.

\section{Referências bibliográficas}

ABC DIGITAL. Piden controlar ingreso de antenas parabólicas. ABC Digital. Disponível em: < http://www.abc.com.py/ nota/piden-controlar-ingreso-de-antenas-parabolicas/>. Acesso em: 20 fev. 2012, 16:37.

ALBUQUERQUE, J.L.C. A dinâmica das fronteiras: deslocamento e circulação dos 'brasiguaios' entre os limites nacionais. Horizontes Antropológicos, vol.15, n.31, 2009, p. 137-166. 
VALVERDE, R.R.H.F. O “paraíso obscuro do mundo": territorialidades ...

ALBUQUERQUE, J.L.C. Conflito e integração nas fronteiras dos brasiguaios. Caderno CRH, Salvador, v. 23, n. 60, Set./Dez. 2010, p.579-590.

ALVAREZ, M. Los brasileños nos imponen su cultura: Victor Pato Brítez habla de los 24 años de Tetãgua, resaltando la ausencia de una política de defensa de nuestra identidad'. Ultima Hora, 09 mai. 2004, p. 39.

BALLER, L. Cultura, identidade e fronteira - Transitoriedade Brasil/Paraguai (1980-2005). Dissertação de Mestrado do Programa de Pós-Graduação em História da Universidade Federal da Grande Dourados, 2008, 186 p.

BOURDIEU, P.; WACQUANT, L. Sobre as artimanhas da razão imperialista. Estudos Afro-Asiáticos, Ano 24, no 1, 2002, p. 1533.

CAPRIGLIONE, L. Brasileiro faz fortuna e má fama no Paraguai. Folha de São Paulo. Disponível em: <http://www1.folha.uol.com. br/fsp/mundo/24140-brasileiro-faz-fortuna-e-ma-fama-no-paraguai .shtml >. Acesso: 05 fev. 2012.

CERVO, A.L. Relações Internacionais da América Latina: velhos e novos paradigmas. Brasilia: IBRI, 2001, 316p.

GALEANO, L.A.; YORE, M. Migrantes Brasileños en Paraguay: principales problemas y demandas. Assunción: Ediciones y Arte S.R.L., 1994, 120p.

GOMES, P.C.C. A dimensão ontológica do território no debate da cidadania: o exemplo canadense. Revista Território, vol. 1, $\mathrm{n}^{\mathbf{o}} 2$, 1997, p.43-62. 
VALVERDE, R.R.H.F. O "paraíso obscuro do mundo": territorialidades ...

HAESBAERT, R. Regiões transfronteiriças e redes brasileiras no Mercosul. Anais do 8o. Encontro de Geógrafos da América Latina. Santiago : Universidad de Chile, 2001, p.

HAESBAERT, R.; SANTA BARBARA, M.J. Identidade e migração em áreas transfronteiriças. GEOgraphia, vol. 3, nº5, 2001, p.33-46.

LA NACION. La 'Naranja Mecánica' acalla la soberbia del seleccionado del 'Maior do Mundo'. La Nación, Asunción, 05 jul. 2010 .

LA NACION. Oi construirá anillo de fibra óptica en el este del país. La empresa proveerá servicio de internet de forma mayorista, según el proyecto acercado a la Conatel. La Nación, Asunción, 21 nov. 2011.

LAINO, D. Fronteiras e penetração brasileira. São Paulo: Global, 1979, 247p.

MACHADO, L.O. Limites, fronteiras e redes. In: STROHAECKER, T. et al. (orgs.) Fronteiras e Espaço Global. Porto Alegre, AGB, 1998, p.41-49.

MACHADO, L.O. Estado, territorialidade, redes: cidades-gêmeas na zona de fronteira sul-americana. In: SILVEIRA, M.L. Continente em Chamas. Rio de Janeiro: Civilização Brasileira, 2005, p. 285-294.

MERCOSUL. Ata $n^{\circ} 2$ da XL Reunião ordinária do Subgrupo de trabalho $\mathrm{n}^{\circ} 1$ - Comunicações. MERCOSUL, 2010. Disponível em: <http://www.ursec.gub.uy/scripts/locallib/imagenes/Act 22010.pd f > . Acesso em: 20 fev. 2012, 09:17.

SACK, R.D. Human Territoriality - Its theory and history. Cambridge: Cambridge University Press, 1986. 256p. 
VALVERDE, R.R.H.F. O "paraíso obscuro do mundo": territorialidades ...

SCHILLER, H.I. Communication and cultural domination. New York: International Arts and Sciences Press, 1976. 127p.

SOUCHARD, S. Pionniers brésiliens au Paraguay. Paris: Kaethala, 2002. 406p.

SOUZA, M.L. O território: sobre espaço e poder, autonomia e desenvolvimento. In: CASTRO, I.E.; CORRÊA, R.L.; GOMES, P.C.C. Geografia - Conceitos e Temas. Rio de Janeiro: Bertrand Brasil, 1995, p. 77-116.

SPRANDEL, M.A. Brasileiros na fronteira com o Paraguai. Estudos Avançados, v. 57, 2006, p. 137-156.

ULTIMA HORA. La cuestión de los inmigrantes brasileños. Ultima Hora, 19/09/2003, p. 24.

VALVERDE, R.R.H.F. Transformações no conceito de território: competição e mobilidade na cidade. GEOUSP - Espaço e Tempo, São Paulo, No 15, 2004, p. 119-126.

Recebido em mio de 2013

Aceito em junho de 2013 